\title{
Leprosos purgate
}

\author{
SUSAN B LIEBESCHUETZ \\ Leeds University Medical School, Leeds LS2 9JT*
}

Accepted for publication 29 March 1988

The motto of Leeds Medical School reads 'Agrotos Sanate, Leprosos Purgate', exhorting students to heal the sick and cleanse the leper. Opportunities to do the latter being distinctly limited in Yorkshire, I was determined to use my 10 -week elective period to learn about the care of patients with not only leprosy, but also other diseases of the developing world.

My destination was the Greenpastures Leprosy Hospital in Pokhara, Nepal. Run by the International Nepal Fellowship, this hospital forms part of the Leprosy Control Project, organized in conjunction with the Nepali government. The hospital is a referral centre for patients from all over Western Nepal, in addition to providing routine care for leprosy patients within its own district.

Nepal, famous for Everest and the Himalayas, is one of the poorest countries in Asia. The mountains which attract trekkers and mountaineers from all over the world, make travel and communications difficult and unpredictable. Distances are measured by the number of days it takes to walk. Despite the provision of rural health posts, many leprosy patients have to walk several days in order to receive treatment.

As the name suggests, Greenpastures Hospital is set in grassy fields which provide grazing for the buffalo of the hospital farm. It is overlooked by the Annapurna range of mountains which appear out of the clouds in the early morning, to give a breath-taking view. There are about 120 beds, patients admitted for foot ulcers or reconstructive surgery being housed in the wards, whilst most of those being treated for leprosy reactions lived in huts in the grounds.

Out-patients were seen by paramedical workers, specifically trained in the diagnosis and routine treatment of leprosy. Those patients with complications or incidental illness were referred for a medical opinion. The majority of patients were admitted either for foot ulcers or reactions, or electively for reconstructive surgery. Those with complicated ulcers requiring septic surgery joined the medical students list. Under the watchful eye of the Nepali theatre technician, I learned to do a number of these simple operations.

Ulcer prevention was the aim of the health education scheme run by the occupational therapy department. This comprised a series of talks and demonstrations about foot, hand and eye care for the patients. Those who had satisfactorily completed the course were awarded a certificate. This

* This account of an elective period by a final year medical student in the UK is in the latest of a series supported for nearly 20 years by LEPRA and more recently by the St Francis Leprosy Guild, 2 The Boltons, London SW10 9SU. Editor 
scheme was still in its infancy when I saw it and still had to prove its value in preventing ulcers, but patients were certainly very keen to join the course and gain the certificate.

In marked contrast to the almost crude procedures in septic surgery, was the refinement of surgical reconstruction. I enjoyed assisting at these very delicate procedures to correct claw hands and foot drop. While the value of these operations in restoring function is self-evident, the cosmetic improvement, in a country where leprosy still carries a great social stigma, is also important. This was illustrated to me by a 22-year-old woman who had a claw hand, but no other signs of leprosy. As I examined her, she became tearful, explaining that her family had been unable to arrange a marriage for her because of her deformity. Clearly, reconstructive surgery could be of great benefit in this case.

While much of my time was spent dealing with leprosy, I had plenty of opportunity to see and treat more general medical problems. A skin clinic was run once a week, where, with the help of a few Nepali phases including 'does it hurt'?, 'does it itch?' and 'how long have you had it', I was able to diagnose most of the commoner presenting problems; scabies and f ungal infections had always to be excluded in any itchy lesion.

Having made a diagnosis, my next problem was to explain to the patient how to use the prescribed treatment. I was rather discouraged when once, despite an elaborate mime explaining how to use potassium permanganate soaks, the patient still turned round to ask if he should drink them.

Tuberculosis is rife in Nepal, its spread being guaranteed by poor nutrition and living conditions and the Nepali habit of spitting constantly. Many patients were being treated for both leprosy and TB. Other, for me, unfamiliar medical problems included a wide range of intestinal infestations, typhoid and kwashiorkor. The latter I saw in the daughter of a leprosy patient, the youngest of a large family. It was rewarding to see her transformed from a miserable and apathetic child to one who was smiling and energetic.

How well then did my elective experiences fulfil the aims and expectations I had held before I went? I certainly learned a lot about the management of leprosy and by the time I left, I felt confident in dealing with its common complications. I also had the opportunity to diagnose and treat patients with a variety of disorders which I would be unlikely to see in the United Kingdom. It was an education to have to learn to have to do without so many of the facilities that I had come to see as 'essential', the lack of equipment for complicated investigations taught me now often it is perf ectly possible to do without. The necessity to re-use and resterilize needles, syringes and gloves until they were unusuable put the current crisis in the UK National Health Service in a different perspective.

\section{Acknowledgments}

I am grateful to the staff of the Greenpastures Hospital for the way in which they made me so welcome, allowing me to become part of the team for a short time, in particular to Dr M Lavender, Dr W Van Braekel and Sister Maria Schimpf. Thanks are also due to the Dora Ratcliffe Fund and the St Francis Leprosy Guild for providing funds to help to finance my elective. 